Ann. Zootech., Ig62, 11 (4), 3II-3I3.

NOTE

\title{
SUR LE SEVRAGE DES PORCELETS A L'AGE DE 5 SEMAINES
}

\author{
E. SALMON-LEGAGNEUR et C. JOUANDET \\ Station de Recherches sur l'Élevage des Porcs \\ Centre national de Recherches zootechniques, Jouy-en-Josas (Seine-et-Oise)
}

Les nombreux échecs rencontrés dans la pratique du sevrage des porcelets à un âge peu avancé (généralement vers 3 semaines) peuvent conđuire à reconsidérer la technique et à envisager pour cette opération un âge plus en rapport avec l'évolution physiologique du jeune animal. Il est clair, en effet, que lorsque toutes les conditions ne sont pas parfaitement favorables, le passage brutal du régime lacté à un aliment complet sec, chez un animal encore mal adapté (insuffisance d'enzymes digestifs, perturbations de la flore intestinale), peut être à l'origine de troubles graves entrâ̂nant des pertes sévères. C'est en général ce qui se passe dans les conditions de l'élevage fermier. Il s'ajoute à cela les difficultés de reproduction que présentent souvent les truies dont la lactation a été interrompue trop tôt.

Des observations préliminaires sur le comportement alimentaire de porcelets sous la mère nous ont montré que, dans les conditions habituelles, la libre consommation d'aliments de sevrage ne devenait importante que vers la $5^{\mathrm{e}}$ semaine (Aumattre et SALMon-LEGagneur, I96r). A cet âge seulement, 1'effet de ces aliments sur la croissance l'emporte sur celui du lait maternel, ce qui peut constituer une indication sur le moment auquel le sevrage précoce est souhaitable.

Nous avons voulu vérifier la validité de cette dernière hypothèse en comparant, dans une première expérience, les résultats de deux groupes de 30 portées de porcelets Large White, dont le premier était sevré à 5 semaines et le second à l'âge classique de deux mois. L'expérience avait lieu dans les conditions de la pratique et les aliments utilisés étaient, respectivement, un aliment de type starter $\left.{ }^{(}{ }^{1}\right)$ contenant $20 \mathrm{p}$. Ioo de M. A. D. et $4500 \mathrm{~K}$. calories $/ \mathrm{kg}$ et un aliment de sevrage classique à $\mathrm{I} 6 \mathrm{p}$. roo de M. A. D. Ces deux aliments, présentés en granulés de $2,5 \mathrm{~mm}$ de diamètre, contenaient des antibiotiques (spiramycine et terramycine) et étaient offerts aux porcelets dès l'âge de 2 semaines.

(1) Sa composition était la suivante en p Ioo; gruau d'avoine 20 , blé 20, manioc Io, tourteau de soja 7 , farine de poisson 8, poudre de lait écrémé Io, levure 5, sucre 10 , saindoux 7 , vitamines et minćraux 3 . 
On enregistrait, chez les porcelets et chez les mères de chaque groupe, les quan. tités d'aliment consommées et les variations de poids au cours de l'expérience. On notait en outre l'état sanitaire des porcelets (mortalité et fréquence des diarrhées) et, chez les truies, la date de retour en oestrus après le sevrage et les résultats de la parturition suivante. L'essentiel de ces résultats est rapporté dans le tableau $\mathrm{I}$.

\section{TABLEAU I}

Comparaison des seorages à 5 semaines et $\dot{a} 2$ mois chez le Pore

\begin{tabular}{|c|c|c|c|c|c|}
\hline \multicolumn{3}{|c|}{ Croissance des porcelets } & \multicolumn{3}{|c|}{ Reproduction des truies } \\
\hline & $\begin{array}{l}\text { Sevrage à } \\
5 \text { semaines }\end{array}$ & $\begin{array}{l}\text { Sevrage à } \\
2 \text { mois }\end{array}$ & & $\begin{array}{l}\text { Sevrage à } \\
5 \text { scmaines }\end{array}$ & $\begin{array}{l}\text { Sevrage à } \\
2 \text { mois }\end{array}$ \\
\hline Nombre de porcelets ....... & 221 & 213 & Sombre de truies.......... & 29 & 30 \\
\hline $\begin{array}{l}\text { l'oids movens à } 5 \text { sem. }(\mathrm{kg}) \text {. } \\
\text { Poids à } 2 \text { mois }(\mathrm{kg}) \ldots \ldots \ldots \text {. . }\end{array}$ & $\begin{array}{c}8,3 \\
19,3(*)\end{array}$ & $\begin{array}{r}8,1 \\
17,9\end{array}$ & $\begin{array}{l}\text { Perte de poids des truies au } \\
\text { cours de la lactation }(\mathrm{kg})\end{array}$ & $16,8\left(^{*}\right)$ & 27,8 \\
\hline $\begin{array}{l}\text { Quantité d'aliments consom- } \\
\text { mée }(\mathrm{kg}) 5 \operatorname{sem} .2 \text { mois . . }\end{array}$ & $17,0 \quad(*)$ & 12,0 & $\begin{array}{l}\text { Quantité d'aliment consom. } \\
\text { pendant la lactation }(\mathrm{kg}) .\end{array}$ & 211 & 357 \\
\hline $\begin{array}{l}\text { Indice de consommation } 5 \\
\text { semaines-2 mois (kg ali- }\end{array}$ & & & $\begin{array}{c}\text { Intervalle sevrage-cestrus } \\
\text { (uombre de jours) } \ldots \ldots \ldots\end{array}$ & $7,9\left(^{*}\right)$ & $6, y^{\prime}$ \\
\hline ment/lergain) ......... & $1,54(*)$ & $1,26(1)$ & Nombre de truies fécondées & 26 & 27 \\
\hline $\begin{array}{l}\text { Indice de consommation cor- } \\
\quad \text { rigé }\left({ }^{2}\right) \ldots \ldots \ldots \ldots \ldots\end{array}$ & 1,$5 ;(*)$ & $3,1 / k$ & $\begin{array}{r}\text { T'aux de fécond. an } 1 \text { er }^{\circ} \text { ostrus } \\
\text { après le sevrage (p. 100). }\end{array}$ & 80 & 73 \\
\hline $\begin{array}{l}\text { Mortalité entre } 5 \text { semaines et } \\
\text { et } 2 \text { mois }(p .100) \quad \ldots \ldots \ldots\end{array}$ & 4,7 & 1,2 & $\begin{array}{l}\text { Intervalle de parturitions (cy- } \\
\text { cle reproduction) nbre de } \mathrm{j}\end{array}$ & $158 \quad(*)$ & 189 \\
\hline $\begin{array}{l}\text { Nbre de jours de diarrhée par } \\
\text { porcelet, } 5 \text { semaines- } 2 \text { mois }\end{array}$ & $1,4\left(^{*}\right)$ & 0,1 & $\begin{array}{c}\text { Nombre de porcelets nés } \\
\text { vivants par portée....... }\end{array}$ & 10,4 & 10,7 \\
\hline
\end{tabular}

(1) Non compris la quantité de lait consommée.

(2) Compte tenu de la quantité d'aliment consommée par la truie vendant la période considérée.

$\left.{ }^{*}\right)$ Différence significative à $\mathrm{P}<0,0$;.

On constate que le sevrage à 5 semaines n'a pas eu d'effet dépressif sur la vitesse de croissance des porcelets, puisqu'en dépit d'une légère augmentation de la fréquence des diarrhées, ceux-ci ont atteint à 2 mois des poids supérieurs à ceux des témoins. On a noté toutefois un gain journalier un peu plus faible au cours de la $5^{\mathrm{e}}$ semaine ( $17^{8}$ g contre 3 I $5 \mathrm{~g}$ chez les témoins), largement compensé par les gains ultérieurs (553 $\mathrm{g}$ contre $428 \mathrm{~g}$, au cours de la $7^{\mathrm{e}}$ semaine). Les quantités d'aliment consommées ont été un peu plus élevées dans le groupe sevré à 5 semaines, surtout à partir de la $6^{\mathrm{e}}$ semaine et il est possible que les quelques cas de diarrhée relevés à cette époque aient pour cause des ingestions trop importantes.

Chez les truies, le sevrage à 5 semaines a permis, outre une réduction de la perte de poids, une économie importante d'aliment pendant la lactation (40 p. IOo). Les facultés de reproduction, jugées au cours de la portée suivante, ne semblent pas avoir été altérées. Compte tenu d'un taux de fécondation un peu plus élevé au premier 
œstrus, les truies sevrées à 5 semaines ont présenté un cycle complet de reproduction (gestation + lactation) plus court de $3 \mathrm{I}$ jours en moyenne. L'augmentation du nombre de porcelets produits qui pourrait en résulter est d'environ I6 p. Ioo.

Ręu pour publication en décembre 1962.

\section{SUMMARY}

A NOTE ABOUT THE WLANING OF PIGLETS AT 5 WEEKS

From a comparison between 29 litters weaned at 5 weeks and 30 litters weaned at 2 months it appears that early weaning results in the following practical advantages : better growth of piglets $(+8 \mathrm{p} .100)$, economy of feed during lactation $(+40 \mathrm{p} .100)$, gain in duration of total reproductive cycle $(+16 \mathrm{p} .100)$.

\section{RÉFÉRENCES BIBLIOGRAPHIQUES}

Aumatre A., Salmon-Legagneur e., ingr. Influence de l'Alimentation complémentaire sur la croissance du porcelet avant le sevrage. Ann. Zoolech. 10, I27-I40. 